\title{
DESEMPENHO ACÚSTICO DE DIVISÓRIAS VERTICAIS EM BLOCOS DE GESSO: UMA AVALIAÇÃO A PARTIR DE MEDIÇÕES DE CAMPO E EM LABORATÓRIO
}

\section{ACOUSTICPERFORMANCE OF VERTICAL PARTITION IN GYPSUMBLOCK: AN EVALUATION IN FIELD AND LABORATORY}

\author{
Otávio Joaquim da Silva Júnior 1 \\ Universidade Federal de Pernambuco, Recife, PE, Brasil, otaviojsjunior@gmail.com \\ José Jéferson do Rêgo Silva ${ }^{2}$ \\ Universidade Federal de Pernambuco, Recife, PE, Brasil, jjregosilva@gmail.com
}

Marco Antonio Silva Pinheiro ${ }^{3}$

Universidade Federal de Santa Maria, Santa Maria, RS, Brasil, marco.pinheiro@smail.ufsm.br

\section{Resumo}

Com a entrada em vigor da norma de desempenho das edificações habitacionais, valores mínimos de desempenho quanto ao isolamento acústico entre cômodos passaram a ser exigidos. $\mathrm{Na}$ busca ao atendimento dessas exigências, muitos construtores têm investido na obtenção de resultados do índice de redução sonora de divisórias em alvenarias de blocos cerâmicos ou concreto. No entanto, elementos construtivos como, por exemplo, paredes em blocos de gesso não têm sido alvo destas investigações com tanto fomento. Na região nordeste do Brasil, onde há uma grande concentração de jazidas naturais de gipsita, muitas construções são feitas em paredes de blocos de gesso, em razão do baixo custo e de condições climáticas da região. Diante da escassez de informações de propriedades acústicas das paredes em blocos de gesso, neste trabalho são apresentados valores do índice de redução sonora ponderado para duas paredes construídas em blocos de gesso maciço com 100mm de espessura, ambas ensaiadas em laboratório conforme métodos preconizados nas normas internacionais ISO 10140. Dos resultados obtidos, as paredes avaliadas em campo atendem a requisitos mínimos da norma brasileira de desempenho (40 dB) apenas nas paredes entre unidades habitacionais autônomas, nas situações onde não há ambiente de dormitório. Em laboratório, a mesma parede atenderá aos requisitos mínimos se for construída como parede cega de salas e cozinhas entre uma unidade habitacional e áreas comuns de trânsito eventual, como corredores e escadaria dos pavimentos (39 db). Os resultados em campo são superiores aos obtidos por ensaio em laboratório, indo de encontro ao que a norma de desempenho prevê. Isso reforça a importância da realização dos ensaios em campo.

Palavras-chave: Desempenho Acústico. Bloco de Gesso. Perda de Transmissão Sonora.

\begin{abstract}
With the coming into effect of the Brazilian standard of performance of residential buildings, minimum performance values as the sound insulation between rooms began to be required. In the search to meet these requirements, many builders have invested in obtaining results of sound reduction index of the partitions masonry ceramic bricks or concrete. However, building elements such as walls in gypsum blocks have not been the subject of such investigations with so much encouraging. In northeastern Brazil, where there is a large concentration of natural deposits of gypsum, many buildings are made of gypsum block walls, due to the climatic conditions of the region and low cost of the material. Considering the lack of information of acoustic properties of the walls in gypsum blocks, this paper presents values of the sound reduction index prepared for two walls constructed of massive plaster blocks $10 \mathrm{~cm}$ thick, both tested in the laboratory according to established methods on international standards ISO 10140. The results obtained of the walls evaluated in the field attend minimum requirements of the Brazilian standard of performance $(40 \mathrm{~dB})$, only as wall between independent dwelling units, in situations where there is no dormitory room. In the laboratory, the same wall meet the minimum requirements if it is built as a blind wall of rooms and kitchens from a housing unit and common areas of eventual transit such as hallways and staircases of the floor (39 db). The field results are superior to those obtained by laboratory test, contrary to the standard of performance expected. This reinforces the importance of conducting the field test.
\end{abstract}

Keywords: Acoustic Performance. Gypsum block. Sound transmission loss. 


\section{Introdução}

A isolação sonora de vedações é hoje uma das informações mais desejadas por projetistas e construtores. Com a publicação em 2013 da quarta edição da NBR 15575 (ASSOCIAÇÃO BRASILEIRA DE NORMAS TÉGNICAS, 2013), em vigor a partir de julho do mesmo ano, conhecer os índices de isolação sonora de vedações internas e/ou externas utilizadas na construção civil passou, do que antes seria uma informação de apreço acadêmico e de alguns poucos empreendimentos, para uma exigência de requisitos mínimos das edificações residenciais, tanto na questão de conforto do usuário como na valorização comercial destas edificações.

Ainda em se tratando de isolação sonora, a redução na densidade da vedação pode promover uma redução também no índice de redução sonora ponderado $\left(\mathrm{R}_{\mathrm{W}}\right)$. No entanto, em estudos realizados por Pinto (2011) verificou-se que materiais menos densos, como tijolo cerâmico vazado, podem apresentar valores ponderados superiores a alvenarias de materiais mais densos, como tijolo maciço.

Aos ensaios realizados em laboratório, entende-se que os resultados são mais precisos, e consequentemente superiores aos resultados obtidos em ensaios realizados em campo, para uma mesma vedação, haja vista que as condições do laboratório são mais bem controladas.

No entanto, ensaios realizados por Ferreira Neto (2009) mostram que os resultados de ensaios realizados em campo, podem ser iguais aos resultados obtidos em laboratório. É o caso da vedação em bloco de concreto com espessura de $90 \mathrm{~mm}$, que possui resultado em campo $\left(D_{n} T, w\right)$ e laboratório $\left(R_{w}\right)$ iguais a $40 \mathrm{~dB}$. Ferreira Neto (2009) mostra ainda que, em alguns casos, os resultados em campo são superiores aos resultados obtidos em laboratório, para um mesmo sistema construtivo. É o caso da vedação em bloco cerâmico com $140 \mathrm{~mm}$ de espessura, que apresentou resultado em laboratório $\left(\mathrm{R}_{\mathrm{w}}\right)$ igual a $39 \mathrm{~dB}$, enquanto que o resultado em campo $\left(\mathrm{D}_{\mathrm{n} T, \mathrm{w}}\right)$ foi de $41 \mathrm{~dB}$.

Nos ensaios realizados em campo as condições de contorno de cada vedação, tais como, portas, esquadrias e revestimento, influenciam diretamente no desempenho acústico do sistema como um todo. A influência do revestimento na isolação sonora da vedação foi estudada por Friedrich (2010), sendo verificado, por meio de ensaios realizados em laboratório, ganhos de até $5 \mathrm{~dB}$ no índice de redução sonora ponderado $\left(\mathrm{R}_{\mathrm{W}}\right)$, em comparação com a vedação sem revestimento.
As vedações comumente utilizadas na construção civil brasileira, caso da alvenaria em blocos cerâmicos e blocos de concreto, possuem resultados de isolação sonora conhecidos e divulgados na construção civil. No guia sobre a norma de desempenho, NBR 15575 (ASSOCIAÇÃO BRASILEIRA DE NORMAS TÉGNICAS, 2013), elaborado pela Câmara Brasileira da Indústria da Construção (2013), são apresentados diversos resultados de isolação sonora de vedações verticais, obtidos através de estudos realizados por distintos grupos de pesquisa. No entanto, o guia não possui informações sobre a isolação sonora de alvenarias executadas com blocos de gesso.

Dada a escassez de informações sobre a isolação sonora promovida por vedações verticais executadas em blocos de gesso, um tipo de vedação bastante utilizada no nordeste brasileiro, este trabalho tem como objetivo primordial caracterizar o desempenho acústico destas vedações, apresentando resultados de ensaios realizados em campo e laboratório.

As vedações executadas em blocos de gesso, se comparadas com alvenarias em tijolo cerâmico, possuem algumas vantagens. Uma delas é a densidade superficial. Segundo Pires Sobrinho et al. (2011), as alvenarias em blocos de gesso são mais leves, variando entre $0,6 \mathrm{kN} / \mathrm{m}$ e $1,0 \mathrm{kN} / \mathrm{m}$, enquanto que as alvenarias tradicionais em blocos cerâmicos revestidas com argamassa, variam entre $1,2 \mathrm{kN} / \mathrm{m}$ e $1,8 \mathrm{kN} / \mathrm{m}$. Isso, de certa forma, contribui para diminuição das cargas permanentes nas lajes/vigas.

Embora a importância desse estudo esteja praticamente voltada para a região Nordeste do Brasil, no qual o Estado de Pernambuco, mais precisamente no polo gesseiro do Araripe, a $680 \mathrm{~km}$ do litoral, responde por cerca de $90 \%$ da produção brasileira de gesso, estimada em dois milhões de toneladas (PERES; BENACHOUR; SANTOS, 2008), pode-se ampliá-la para regiões vizinhas.

\section{Critérios, ambientes e equipamentos utilizados nos ensaios}

Os ensaios de isolação sonora, em campo e laboratório, foram realizados em paredes executadas em blocos de gesso maciço, assentados com cola de gesso. Os blocos de gesso possuem $666 \mathrm{~mm}$ de largura (dimensão paralela ao piso), $500 \mathrm{~mm}$ de altura (dimensão perpendicular ao piso) e espessura de $100 \mathrm{~mm}$.

A fim de obter-se resultados de isolação sonora sem influência de fatores externos, foram realizados ensaios 
em laboratório em duas vedações distintas, utilizando os mesmos tipos de bloco de gesso.

A perda de transmissão sonora dos blocos de gesso, representada pelo $\mathrm{R}_{\mathrm{w}}$, foi obtida utilizando-se os resultados de ensaios realizados em câmaras reverberantes do laboratório de acústica da Universidade Federal de Santa Maria (UFSM).

As câmaras reverberantes possuem volumes de $60 \mathrm{~m}$ e $67 \mathrm{~m}$, separadas por um pórtico em concreto com $55 \mathrm{~cm}$ de espessura. As paredes e lajes das câmaras são em concreto armado com $30 \mathrm{~cm}$ de espessura e cada câmara possui porta dupla, em chapa de aço de $12,7 \mathrm{~mm}$ de espessura, $1,50 \mathrm{~m}$ de largura e $2,50 \mathrm{~m}$ de altura, vedada com borracha em todo o seu contorno, fechada sob pressão, garantindo assim uma perfeita estanqueidade. As superfícies das câmaras não são paralelas, permitindo um campo difuso. A estrutura das câmaras é apoiada sobre isoladores em polímero, neoprene, os quais são apoiados em pilaretes. A Figura 1 ilustra uma representação gráfica da câmara reverberante da Universidade Federal de Santa Maria (UFSM).

Figura 1 - Planta baixa e corte longitudinal das câmaras reverberantes
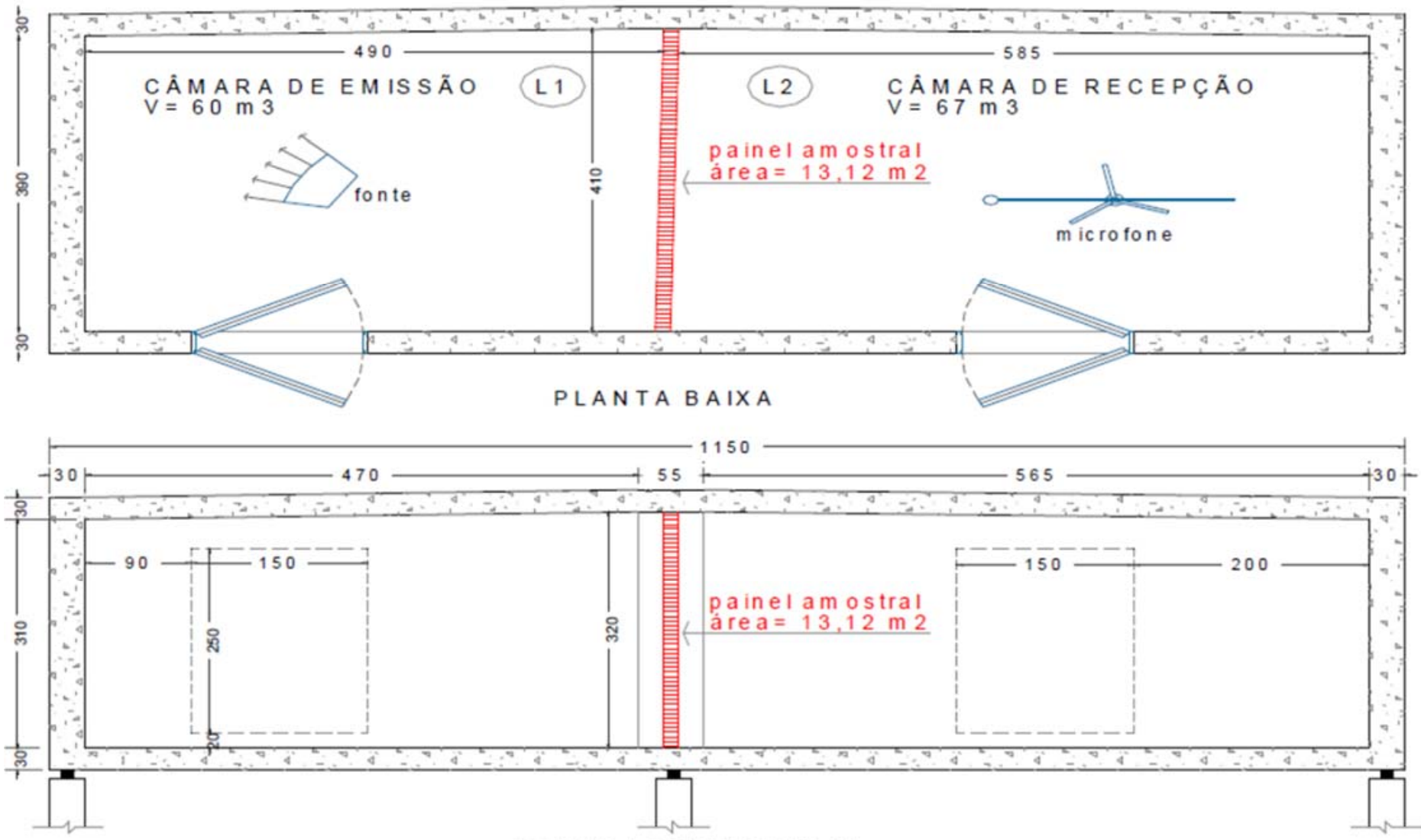

CORTE LONGITUDINAL

Fonte: Santos (2006)

Para realização dos ensaios em laboratório foram seguidos os procedimentos descritos nas normas ISO 10140, partes 1,2 e 4 (INTERNATIONAL ORGANIZATION FOR STANDARDIZATION, 2010a, 2010b, 2010c).

Os ensaios de isolamento acústico promovido por vedação vertical interna, executada em bloco de gesso com espessura de $100 \mathrm{~mm}$, foram realizados em campo, sendo analisadas 6 vedações em apartamentos situados em diferentes andares, em duas situações distintas.

$\mathrm{Na}$ primeira situação (VVI1) foi avaliada uma vedação com 8,00m, divisória entre salas de apartamentos geminados, revestida em ambas as partes com massa corrida. A vedação possuía travamento lateral em pilares estruturais, sobre o piso e sob viga estrutural com cola de gesso. Nesta situação foram realizados quatro ensaios em vedações distintas.

A segunda situação (VVI2) avaliada foi uma vedação divisória entre a sala e o quarto de apartamentos distintos, revestida em ambas as partes com massa corrida. A vedação possuía travamento lateral em pilares estruturais, sobre o piso e sob viga estrutural com cola de gesso. A vedação possui área de aproximadamente 
$5,00 \mathrm{~m}$. Nesta situação foram realizados ensaios em duas vedações distintas.

Os ensaios realizados em campo, para avaliação do desempenho acústico das vedações verticais internas executadas em bloco de gesso, seguiram os procedimentos de ensaio descritos na norma ISO 140-4 (INTERNATIONAL ORGANIZATION FOR STANDARDIZATION, 1998), conforme especificado pela NBR 15575-4 (ASSOCIAÇÃO BRASILEIRA DE NORMAS TÉGNICAS, 2013). O valor único de isolamento, Diferença Padronizada de Nível Ponderada $\left(\mathrm{D}_{\mathrm{nT}, \mathrm{w}}\right)$ foi obtido conforme preconizado na norma ISO 717-1 (INTERNATIONAL ORGANIZATION FOR STANDARDIZATION, 2013).

As medições de recepção foram realizadas em 3 pontos distintos, sendo respeitadas as distâncias mínimas de $0,7 \mathrm{~m}$ entre posições do microfone e $0,5 \mathrm{~m}$ entre o microfone e quaisquer superfícies refletoras. Tanto a fonte emissora de ruído quanto o microfone foram posicionados numa altura de $1,2 \mathrm{~m}$ em relação ao piso.

Os ensaios foram realizados utilizando os equipamentos: Medidor de nível de pressão sonora 2270, Bruel \& Kjaer (em campo e laboratório); Fonte emissora de ruído dodecaedro Omni 12 e um amplificador, marca $01 \mathrm{~dB}$ (em campo); fonte sonora omnidirecional tipo 4292; amplificador de potência tipo 2716 para fonte sonora, Bruel \& Kjaer (em laboratório); rotating boom tipo 3923, Bruel \& Kjaer (em laboratório).

No anexo F da NBR 15575-4 (ASSOCIAÇÃO BRASILEIRA DE NORMAS TÉGNICAS, 2013) são apresentados os valores de Índice de Redução Sonora Ponderado $\mathrm{R}_{\mathrm{w}}$ (ensaios em laboratório) e a Diferença Padronizada de Nível Ponderada promovida pelas vedações verticais entre ambientes $\mathrm{D}_{\mathrm{nT}, \mathrm{w}}$ de componentes construtivos utilizados nas vedações entre ambientes para cada elemento.

A Tabela 1 apresenta valores de índice de redução sonora ponderado $\left(\mathrm{R}_{\mathrm{w}}\right)$ e da Diferença Padronizada de Nível Ponderada promovida pelas vedações verticais entre ambientes ( $\mathrm{D}_{\mathrm{nT}, \mathrm{w}}$ ) para alguns elementos de vedação e seus respectivos níveis de desempenho.

\section{Resultados e discussões}

Os resultados obtidos através dos ensaios realizados em campo e laboratório foram confrontados entre si e também comparados com os requisitos preconizados na NBR 15575-4 (ASSOCIAÇÃO BRASILEIRA DE NORMAS TÉGNICAS, 2013).

Os ensaios de isolação sonora foram realizados em duas vedações (ensaio 1 e ensaio 2), ambas executadas com os mesmos tipos de blocos de gesso. Nos dois ensaios foram obtidos o mesmo Índice de redução sonora ponderado, $R_{\mathrm{w}}$ igual a $39 \mathrm{~dB}$.

Tabela 1 - Índice de redução sonora ponderado $R_{w}$ e Diferença Padronizada de Nivel Ponderada $\mathrm{D}_{\mathrm{n}, \mathrm{w}}$ de alguns componentes construtivos utilizados nas vedações entre ambientes - NBR 15575-4: 2013

\begin{tabular}{|c|c|c|c|}
\hline Elemento & $R_{w}(d B)$ & $\begin{array}{l}\text { DnT,w } \\
\text { (dB) }\end{array}$ & $\begin{array}{c}\text { Nível de } \\
\text { desempenho }\end{array}$ \\
\hline \multirow{3}{*}{$\begin{array}{l}\text { Parede entre unidades } \\
\text { habitacionais autônomas } \\
\text { (parede de geminação), nas } \\
\text { situações onde não haja } \\
\text { ambiente de dormitório }\end{array}$} & 45 a 49 & 40 a 44 & Mínimo \\
\hline & 50 a 54 & 45 a 49 & Intermediário \\
\hline & $\geq 55$ & $\geq 50$ & Superior \\
\hline \multirow{3}{*}{$\begin{array}{l}\text { Parede entre unidades } \\
\text { habitacionais autônomas } \\
\text { (parede de geminação), no } \\
\text { caso de pelo menos um dos } \\
\text { ambientes ser dormitório }\end{array}$} & 50 a 54 & 45 a 49 & Mínimo \\
\hline & 55 a 59 & 50 a 54 & Intermediário \\
\hline & $\geq 60$ & $\geq 55$ & Superior \\
\hline \multirow{3}{*}{$\begin{array}{c}\text { Parede cega de salas e } \\
\text { cozinhas entre uma unidade } \\
\text { habitacional e áreas comuns de } \\
\text { trânsito eventual, como } \\
\text { corredores e escadaria dos }\end{array}$} & 35 a 39 & 30 a 34 & Mínimo \\
\hline & 40 a 44 & 35 a 39 & Intermediário \\
\hline & $\geq 45$ & $\geq 40$ & Superior \\
\hline
\end{tabular}

Fonte: NBR 15575-4:2013

Com o valor de $39 \mathrm{~dB}$ as vedações em blocos de gesso maciço com espessura de $100 \mathrm{~mm}$ só poderiam ser utilizadas em parede cega de salas e cozinhas entre uma unidade habitacional e áreas comuns de trânsito eventual, como corredores e escadaria dos pavimentos, conforme se pode identificar na Tabela 2.

Tabela 2 - Resultado de isolação sonora promovida pela vedação em bloco de gesso $-R_{w}$

\begin{tabular}{cccc}
\hline Elemento & Ensaio & Resultados & $\begin{array}{c}\text { Nível de } \\
\text { desempenho }\end{array}$ \\
\hline $\begin{array}{c}\text { Parede entre unidades } \\
\text { habitacionais autônomas } \\
\text { (parede de geminação), nas } \\
\text { situações onde não haja } \\
\text { ambiente de dormitório }\end{array}$ & 1 & 39 & Não atende \\
\cline { 2 - 4 } & 2 & 39 & Não atende \\
\hline $\begin{array}{c}\text { Parede entre unidades } \\
\text { habitacionais autônomas } \\
\text { (parede de geminação), no } \\
\text { caso de pelo menos um dos } \\
\text { ambientes ser dormitório }\end{array}$ & 1 & 39 & Não atende \\
\hline $\begin{array}{c}\text { Parede cega de salas e } \\
\text { cozinhas entre uma unidade } \\
\text { habitacional e áreas comuns } \\
\text { de trânsito eventual, como } \\
\text { corredores e escadaria dos } \\
\text { pavimentos }\end{array}$ & 1 & 39 & Não atende \\
\hline Fonny & 2 & 39 & Mínimo \\
\hline
\end{tabular}

Fonte: Os autores

A Figura 2 apresenta graficamente os valores de Índice de redução sonora $\mathrm{R}$ para cada faixa de frequência, em bandas de terço de oitava, dos dois ensaios realizados em laboratório. 
O gráfico apresentado na Figura 2 mostra um comportamento levemente diferente nas altas e baixas frequências, no entanto, as duas curvas possuem um comportamento muito similar.

Os ensaios realizados em campo foram executados em duas vedações distintas, VVI1 e VVI2. Na VVI1 foram realizados 4 ensaios e na VVI2 foram realizados 2 ensaios, em paredes distintas. Os resultados e a avaliação de desempenho, conforme NBR 15575-4 (ASSOCIAÇÃOO BRASILEIRA DE NORMAS TÉGNICAS, 2013), são apresentados na Tabela 3.

Figura 2 - Índice de redução sonora R das duas vedações em bloco de gesso ensaiadas

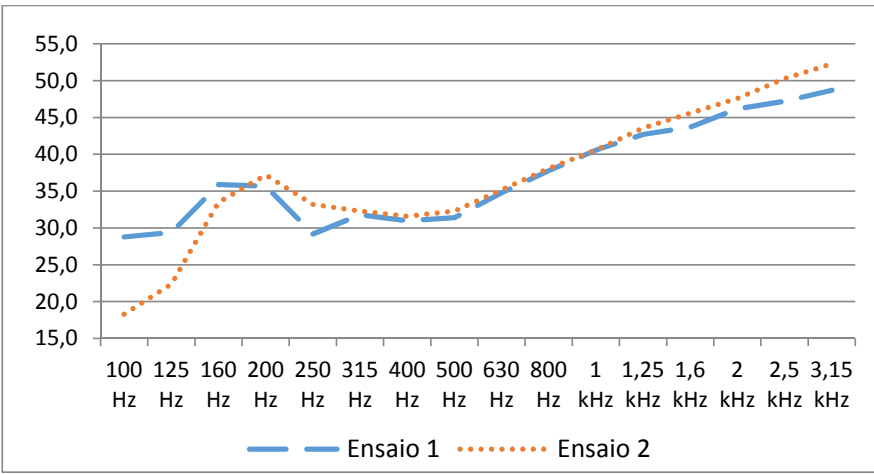

Fonte: Os autores

Tabela 3 - Resultado isolamento acústico promovido por vedação vertical executada em bloco de gesso $-D_{n T, w}$

\begin{tabular}{|c|c|c|c|}
\hline Elemento & Ensaio & Resultados & $\begin{array}{c}\text { Nível de } \\
\text { desempenho }\end{array}$ \\
\hline \multirow{4}{*}{$\begin{array}{c}\text { Parede entre unidades } \\
\text { habitacionais autônomas } \\
\text { (parede de geminação), } \\
\text { nas situações onde não } \\
\text { haja ambiente de } \\
\text { dormitório }\end{array}$} & 3 & 40 & Mínimo \\
\hline & 4 & 40 & Mínimo \\
\hline & 5 & 39 & Não atende \\
\hline & 6 & 40 & Mínimo \\
\hline \multirow{2}{*}{$\begin{array}{c}\text { Parede entre unidades } \\
\text { habitacionais autônomas } \\
\text { (parede de geminação), } \\
\text { no caso de pelo menos } \\
\text { um dos ambientes ser } \\
\text { dormitório }\end{array}$} & 7 & 43 & Não atende \\
\hline & 8 & 44 & Não atende \\
\hline
\end{tabular}

\section{Fonte: Os autores}

Conforme pode ser observado na Tabela 3, o desempenho mínimo é atingido em 3 vedações ensaiadas na situação onde não haja ambiente de dormitório. Já as duas vedações ensaiadas, na situação onde haja pelo menos um ambiente de dormitório, não atendem ao desempenho mínimo preconizado na NBR 15575-4 (ASSOCIAÇÃO BRASILEIRA DE NORMAS TÉGNICAS, 2013).

A Figura 3 apresenta, graficamente, os valores de Diferença padronizada de nível em cada banda de terço de oitava dos 4 ensaios realizados nas vedações verticais entre salas de apartamentos distintos.
Os resultados apresentados na Figura 3 mostram um comportamento praticamente idêntico das quatro vedações avaliadas. Apenas no ensaio 5, resultado com menor valor de $\mathrm{D}_{\mathrm{nT}, \mathrm{w}}$, observa-se uma redução, em relação às demais, nas faixas entre $500 \mathrm{~Hz}$ e $1,25 \mathrm{kHz}$. Nota-se ainda, em todos os ensaios, uma redução na Diferença padronizada de nível a partir de $2 \mathrm{kHz}$.

Figura 3 - Diferença padronizada de nível $D_{n T}$ das quatro vedações em bloco de gesso ensaiadas na VVI1

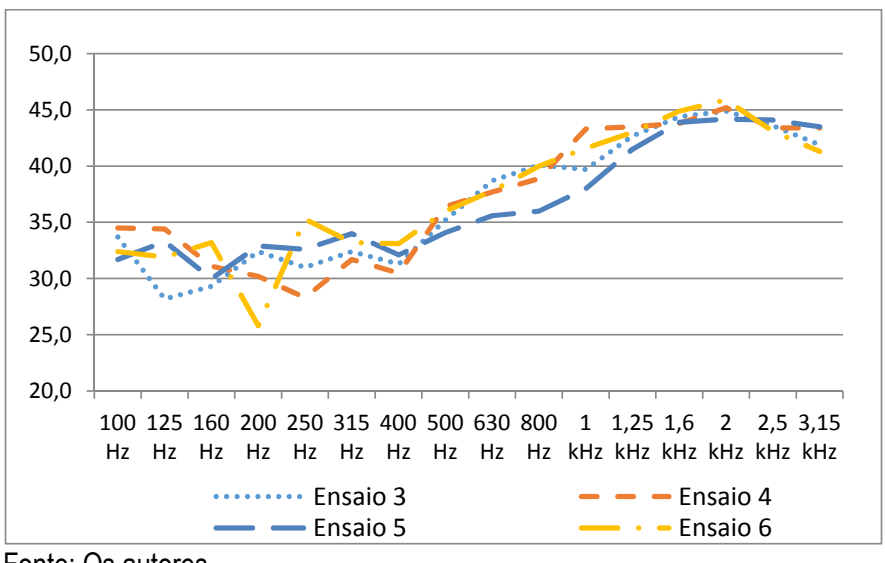

Fonte: Os autores

Na Figura 4 são apresentados os valores de Diferença padronizada de nível em cada banda de terço de oitava dos 2 ensaios realizados nas vedações verticais entre a sala e o dormitório de apartamentos distintos.

Figura 4 - Diferença padronizada de nível $D_{n T}$ das duas vedações em bloco de gesso ensaiadas na VVI2

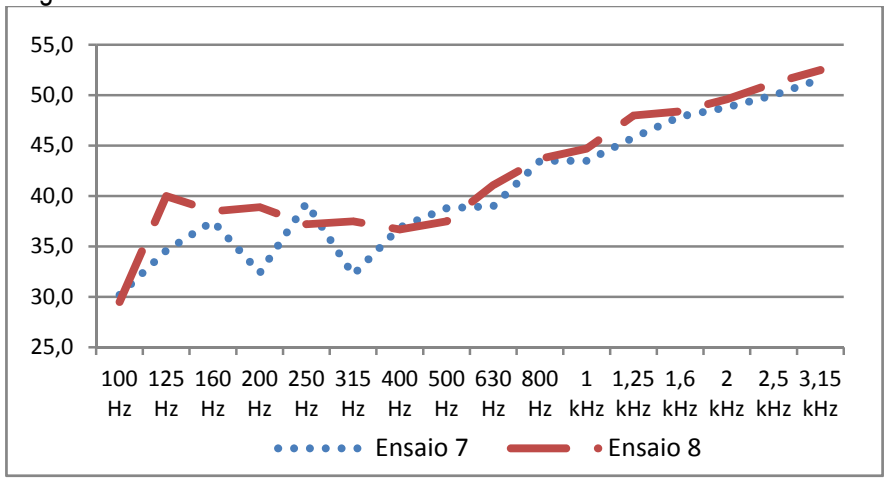

Fonte: Os autores

Conforme pode ser observado na Figura 4, os resultados obtidos no ensaio 7 apresentam valores de $\mathrm{D}_{\mathrm{n}} \mathrm{T}$ menores que o ensaio 8 nas baixas frequências, de $100 \mathrm{~Hz}$ a $400 \mathrm{~Hz}$, contribuído para o menor valor de $\mathrm{D}_{\text {nT,w. }}$ A partir de $400 \mathrm{~Hz}$ o isolamento acústico das duas vedações passa a ser praticamente igual em todas as faixas de frequência.

Colocando num único gráfico todos os 8 resultados de isolação sonora (Figura 5), pode-se observar a similaridade dos resultados. 
$\mathrm{Na}$ figura 5, os ensaios 1 e 2 são de laboratório. Os ensaios 3, 4, 5 e 6 são de campo, realizados entre salas, e os ensaios 7 e 8 são de campo, realizados entre sala e dormitório.

Analisando os gráficos da figura 5, observa-se uma queda na diferença padronizada de nível da VVI1 (ensaios 3, 4, 5 e 6) a partir de $2 \mathrm{kHz}$, o que não ocorre nos demais ensaios, VVI2 e ensaio em laboratório.

Figura 5 - Isolação sonora em bandas de terço de oitava de todos os ensaios realizados, em campo e laboratório

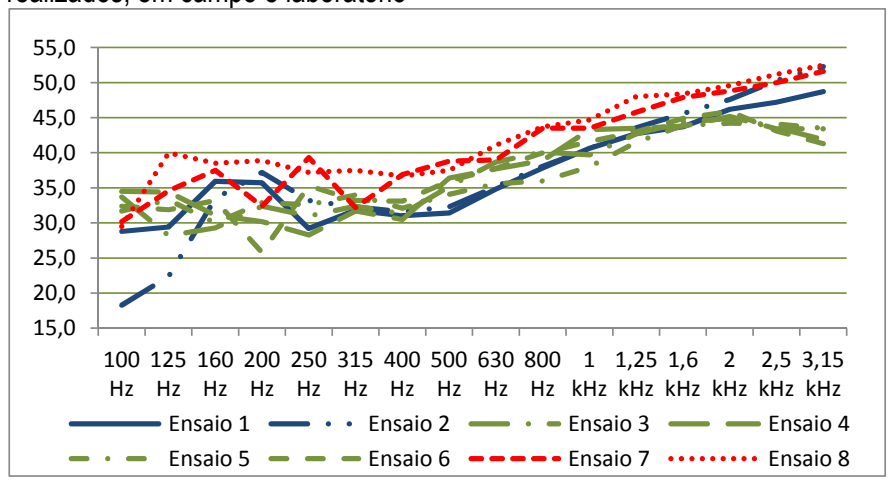

Fonte: Os autores

\section{Considerações finais}

Exigências quanto ao desempenho acústico de edificações têm sido maiores nas construções habitacionais brasileiras. No Nordeste deste país, vedações construtivas em gesso são de grande importância para a região, dada a maior velocidade de execução e menor espessura de acabamento.
Identificou-se neste trabalho que paredes em gesso avaliadas no local (ensaios de campo) enquadram-se, conforme norma brasileira de desempenho, em "Parede entre unidades habitacionais autônomas (parede de geminação), nas situações onde não haja ambiente de dormitório". No entanto, para o caso de medições em laboratório, as vedações verticais em bloco de gesso atendem apenas à situação de "Parede cega de salas e cozinhas entre uma unidade habitacional e áreas comuns de trânsito eventual, como corredores e escadaria dos pavimentos". Em ambas as situações, o desempenho é qualificado como mínimo.

Entende-se que este desempenho foi obtido devido principalmente ao menor isolamento nas bandas de baixa frequência, em razão da densidade do gesso. No entanto, embora se tenha atingido somente o desempenho mínimo, as paredes em blocos de gesso são uma alternativa tecnicamente e economicamente viável para algumas regiões do Brasil.

Conforme apresentado neste trabalho, os resultados de isolamento acústico ( $\mathrm{D}_{\mathrm{nT}, \mathrm{w}}$ ), ensaios de campo, são superiores aos resultados dos ensaios realizados em laboratório $\left(\mathrm{R}_{\mathrm{w}}\right)$, divergindo do que prevê a norma de desempenho (NBR 15575), onde os critérios para ensaios em laboratório estão $5 \mathrm{~dB}$ acima dos critérios exigidos para vedações ensaiadas em campo. Este fato reforça a importância da realização de ensaios em campo, que podem, em algumas situações, atender ao desempenho desejado, mas que não foi atendido no ensaio realizado em laboratório.

\section{Agradecimentos}

Os autores registram seus sinceros agradecimentos à UFPE e a UFSM, pelo apoio ao projeto de mestrado do primeiro autor; A FACEPE pelo auxílio financeiro na realização dos ensaios, concedido ao primeiro autor.

\section{Notas}

(1) Os resultados apresentados neste trabalho foram desenvolvidos durante o mestrado do primeiro autor e originalmente apresentado no XXV Encontro da Sociedade Brasileira de Acústica, SOBRAC 2014 (SILVA JUNIOR; REGO SILVA; PINHEIRO, 2014). Este trabalho é uma versão atualizada e ampliada do artigo original.

\section{Referências}

ASSOCIAÇÃO BRASILEIRA DE NORMAS TÉCNICAS. NBR15575-4: Edificações habitacionais - desempenho - Parte 4: Requisitos para vedações verticais internas e externas -- SVVIE. Rio de Janeiro: ABNT, 2013.

CÂMARA BRASILEIRA DA INDÚSTRIA DA CONSTRUÇÃO. Desempenho de edificações habitacionais - guia orientativo para atendimento à norma ANBT NBR 15575/2013. Brasília, 2013. 162 p. 
FERREIRA NETO, Maria de Fátima. Nível de conforto acústico: uma proposta para edifícios residenciais. 2009. 257 f. Tese (Doutorado em Engenharia Civil) - Programa de Pós-Graduação da Faculdade de Engenharia Civil, Arquitetura e Urbanismo, Universidade Estadual de Campinas, Campinas, São Paulo, 2009.

FRIEDRICH, Adriana Flores. Avaliação da contribuição do revestimento na isolação sonora de paredes de alvenaria. 2010. 112 f. Dissertação (Mestrado em Engenharia Civil) - Programa de Pós-Graduação do Centro de Tecnologia, Universidade Federal de Santa Maria, Santa Maria, Rio Grande do Sul, 2010.

INTERNATIONAL ORGANIZATION FOR STANDARDIZATION. ISO 140-4 Acoustics -- Measurement of sound insulation in buildings and of building elements -- Part 4: Field measurements of airborne sound insulation between rooms. Geneva, 1998.

ISO 717-1 Acoustics -- Rating of sound insulation in buildings and of building elements -- Part 1: Airborne sound insulation. Geneva, 2013.

.ISO 10140-1 Acoustics - Laboratory measurement of sound insulation of building elements - Part 1: Application rules for specific products. Geneva, 2010a.

. ISO 10140-2 Acoustics -- Laboratory measurement of sound insulation of building elements -- Part 2: Measurement of airborne sound insulation. Geneva, 2010b

ISO 10140-4 Acoustics -- Laboratory measurement of sound insulation of building elements -- Part 4: Measurement procedures and requirements. Geneva, 2010c.

SILVA JÚNIOR, O.J.; REGO SILVA, J.J.; PINHEIRO, M.A.S. Desempenho acústico de vedações verticais em blocos de gesso: uma avaliação em campo e laboratório. In: ENCONTRO DA SOCIEDADE BRASILEIRA DE ACÚSTICA, 25., 2014, Campinas. Anais ... Campinas: UNICAMP, 2014.

PERES, L.; BENACHOUR, M.; SANTOS, V.A. Gesso: Produção e utilização na construção civil. SEBRAE, Recife, 2008.

PINTO, Rodrigo Barcelos. Determinação experimental e numérica da redução sonora aérea em paredes de alvenaria utilizadas em habitações. 2011.97 f. Dissertação (Mestrado em Engenharia Civil) - Programa de Pós-Graduação do Centro de Tecnologia, Universidade Federal de Santa Maria, Santa Maria, Rio Grande do Sul, 2011.

PIRES SOBRINHO, Carlos Welligton de Azevedo et al. Divisórias internas de edifícios em alvenaria de blocos de gesso: vantagens técnicas, econômicas e ambientais. 2011. CBIC :: Sala de Imprensa :: Artigos. Disponível em: http://www.cbic.org.br/print/5810. Acesso em: 02 out. 2014.

SANTOS NETO, Nestor Alves. Caracterização do isolamento acústico de uma parede de alvenaria estrutural de blocos cerâmicos. 2006. 128f. Dissertação (Mestrado em Engenharia Givil). - Programa de Pós-Graduação do Centro de Tecnologia, Universidade Federal de Santa Maria, Santa Maria, Rio Grande do Sul, 2006.

\footnotetext{
${ }^{1}$ Otávio Joaquim da Silva Júnior

Engenheiro Civil. Mestre. Endereço postal: Rua Nossa Senhora do Carmo, 30, Jaboatão dos Guararapes, PE, Brasil, CEP: 54330-220.

${ }^{2}$ José Jéferson do Rêgo Silva

Engenheiro Civil. Doutor. Endereço postal: Av. Prof. Moraes Rego, 1235, Recife, PE, Brasil, CEP: 50670-901.

${ }^{3}$ Marco Antonio Silva Pinheiro

Engenheiro Civil. Doutor. Endereço postal: Av. Roraima, 1000, Santa Maria, RS, Brasil, CEP: 97105-900.
} 